\title{
Remote ischemic preconditioning differentially affects NADPH oxidase isoforms during hepatic ischemia-reperfusion
}

\author{
Dénes Garab ${ }^{\mathrm{a}}$, Ngwi Fet ${ }^{\mathrm{b}}$, Andrea Szabó ${ }^{\mathrm{a}}$, René H. Tolba ${ }^{\mathrm{b}}$, Mihály Boros ${ }^{\mathrm{a}}$, Petra Hartmann ${ }^{\mathrm{a}, *}$ \\ a Institute of Surgical Research, University of Szeged, Szeged, Hungary \\ ${ }^{\mathrm{b}}$ Institute of Laboratory Animal Science and Experimental Surgery, RWTH Aachen University, Aachen, Germany
}

\section{A R T I C L E I N F O}

\section{Article history:}

Received 16 January 2014

Accepted 7 April 2014

Available online 24 April 2014

\section{Keywords:}

NOX2

NOX4

Microcirculation

Inflammation

Intravital video microscopy

Modified spectrophotometry

Polymorphonuclear leukocytes

\begin{abstract}
A B S T R A C T
Aims: We investigated the function of major superoxide-generating enzymes after remote ischemic preconditioning (IPC) and hepatic ischemia-reperfusion (IR), with the specific aim of assessing the importance of the most relevant NADPH oxidase (NOX) isoforms, NOX2 and NOX4, in the mechanism of action.

Main methods: 60-min partial liver ischemia was induced in Sprague-Dawley rats in the presence or absence of remote IPC $(2 \times 10$-min limb IR), and hepatic microcirculatory variables were determined through intravital video microscopy and lightguide spectrophotometry during reperfusion. Inflammatory enzyme activities (myeloperoxidase (MPO) and xanthine oxidoreductase (XOR)), cytokine production (TNF- $\alpha$ and HMGB-1), liver necroenzyme levels (AST, ALT and LDH) and NOX2 and NOX4 protein expression changes (Western blot analysis) were assayed biochemically.

Key findings: In this setting, remote IPC significantly decreased the IR-induced hepatic NOX2 expression, but the NOX4 expression remained unchanged. The remote IPC provided significant, but incomplete protection against the leukocyte-endothelial cell interactions and flow deterioration. Hepatocellular damage (AST, ALT and LDH release), cytokine levels, and XOR and MPO activities also diminished.

Significance: Remote IPC limited the IR-induced microcirculatory dysfunction, but the protective effect did not affect all NOX homologs (at least not NOX4). The residual damage and inflammatory activation could well be linked to the unchanging NOX4 activity.
\end{abstract}

(C) 2014 Elsevier Inc. All rights reserved.

\section{Introduction}

The application of repetitive short periods of ischemia, referred to as ischemic preconditioning (IPC), is a well-established approach to the achievement of increased ischemic tolerance in various tissues. Interestingly, remote, inter-organ IPC also confers protection against subsequent ischemia-reperfusion (IR) injury (Koti et al., 2002). The elements and the sequence of events through which IPC exerts distant beneficial effects have not been fully explored, but adaptation of the gene expression of the cellular redox homeostasis is one of the key protective mechanisms through which a lower degree of radical formation can be attained in the endothelial compartment (Koti et al., 2002; Mallick et al., 2005). Signaling processes catalyzed by oxygen and nitrogen radical-producing enzymes, including neuronal nitric oxide synthase (nNOS), endothelial NOS (eNOS) and xanthine oxidase (XO) (Abu-Amara et al., 2011; Yuan et al., 2012), have been demonstrated in the course of defensive action

\footnotetext{
* Corresponding author at: Institute of Surgical Research, University of Szeged, Szőkefalvi-Nagy Béla u. 6., H-6720 Szeged, Hungary. Tel.: + 3662 545103; fax: + 3662 545743.

E-mail address: hartmann.petra@med.szote.u-szeged.hu (P. Hartmann).
}

of IPC, and a number of additional data have also established the decisive roles of NADPH oxidases (NOXs) (Wang et al., 2007; Tejima et al., 2007). With variation in the catalytic subunits, the NOXs comprise 7 family members (NOX1 to NOX5 and DUOX1 and DUOX2), which exhibit tissue-specific differences in their baseline expression (Bedard and Krause, 2007). In the case of liver parenchyma, NOX2 and NOX4 proteins have been found in hepatocytes, NOX2 predominates in the Kupffer cells, while NOX4 is more abundant in the microvessels (Bengtsson et al., 2003; Ellmark et al., 2005). Furthermore, the expression of NOX4 is at least 20 -fold greater than that of NOX2 in the endothelial cells (Sorescu and Griendling, 2002), while the expression of NOX2 cannot be detected in the vascular smooth muscle cells (Görlach et al., 2000; Lassègue et al., 2001).

NOXs are specifically activated by many stimuli that are known to cause an endothelial dysfunction (Anilkumar et al., 2009), and previous studies have provided evidence of elevated mRNA levels of both NOX2 and NOX4 in response to a liver IR injury (Marden et al., 2008). Moreover, the mortality rate due to hepatic ischemia was reduced in NOX2-deficient mice (Harada et al., 2004) and the role of the phagocytic form of NOX in Kupffer cells has been demonstrated after preconditioning with a chemical agent that induces hypoxia (Tejima et al., 2007). Collectively, these data suggest that influencing NOX4 (derived from hepatocytes and/or 
vascular cells) and NOX2 (produced by phagocytic PMN leukocytes and/ or Kupffer cells) may contribute to the protective mechanism of remote IPC. We therefore hypothesized that the effects of remote IPC can be linked to an alleviated inflammatory reaction in the postischemic hepatic microcirculation associated with NOX2 and NOX4 activation. To address this issue, we set out to investigate the consequences of limb IPC on major intracellular superoxide-generating enzyme systems in a rat model of hepatic IR injury, with special emphasis on changes in expression of NOX2 and NOX4 proteins.

\section{Materials and methods}

The experiments were carried out on male Sprague-Dawley rats (Charles River, Sulzfeld, Germany; average weight $300 \pm 20$ g) housed in an environmentally controlled room with a 12-h light-dark cycle, and kept on commercial rat chow (Charles River, Wilmington, MA, USA) and tap water ad libitum. The experimental protocol was in accordance with EU directive 2010/63 for the protection of animals used for scientific purposes and was approved by the Animal Welfare Committee of the University of Szeged. This study also complied with the criteria of the US National Institutes of Health Guidelines for the Care and Use of Laboratory Animals.

\section{Surgical procedures}

Anesthesia was induced with a combination of $25 \mathrm{mg} \mathrm{ml}^{-1}$ (S)-ketamine (Ketanest; Parke Davis, Berlin, Germany) and $20 \mathrm{mg} \mathrm{ml}^{-1}$ xylazine (Rompun; Bayer, Leverkusen, Germany) in a ratio of 8:1, injected i.p. and sustained with small supplementary i.v. doses every $30 \mathrm{~min}$. The trachea was intubated to facilitate respiration, and the right jugular vein and carotid artery were cannulated for fluid and drug administration and for the measurement of arterial pressure, respectively. The animals were placed in a supine position on a heating pad to maintain the body temperature between 36 and $37{ }^{\circ} \mathrm{C}$, and lactated Ringer's solution was infused at a rate of $10 \mathrm{ml} \mathrm{kg}^{-1} \mathrm{~h}^{-1}$ during the experiment.

Before surgery, the fur over the abdomen was shaved, and the skin was disinfected with povidone iodide. After midline laparotomy and bilateral subcostal incisions, the liver was carefully freed from all ligamentous attachments and the liver was exposed and the left branches of the portal vein and the hepatic artery were mobilized. Complete ischemia of the median and left hepatic lobes was achieved by clamping the left lateral branches of the hepatic artery and the portal vein with a microsurgical clip for $60 \mathrm{~min}$. After the ischemic period, the clips were removed and the wound was temporarily covered with water-impermeable foil during the 180-min reperfusion period (Taniguchi et al., 2007).

\section{Experimental protocols}

The experiments were performed in two major series, with the animals randomly assigned to one or another of the following experimental groups. In the first series, we evaluated the microcirculatory consequences of partial hepatic ischemia by using the noninvasive modified spectrometric $\mathrm{O} 2 \mathrm{C}$ method ( $\mathrm{O} 2 \mathrm{C}$ system, see later). In one group, the hepatic microcirculatory responses to 60 -min complete ischemia followed by a 180 -min reperfusion period were examined (IR group, $\mathrm{n}=6$ ). After recording of the baseline microcirculatory variables $(t=-100 \mathrm{~min})$, ischemia was induced in the median and left hepatic lobes. The occlusions were then released ( $\mathrm{t}=0 \mathrm{~min})$, and the microcirculation in the affected lobes was observed via $\mathrm{O} 2 \mathrm{C}$ at $\mathrm{t}=$ 60,120 and $180 \mathrm{~min}$ in the reperfusion phase. In another group, 2 cycles of a 10-min complete hindlimb ischemia and 10-min reperfusion was used as a preconditioning trigger before the induction of liver ischemia (remote IPC + IR group, $n=6$ ). Limb ischemia was achieved by placing a tourniquet around the proximal femur, with simultaneous occlusion of the femoral artery with a miniclip (Szabó et al., 2009). The animals in a third group were subjected to the same surgical procedures, except for the induction of liver or limb ischemia (Sham group, $n=6$ ). Blood samples for biochemical determinations were taken at $\mathrm{t}=0,60,120$ and $180 \mathrm{~min}$ of the experiments. Tissue biopsies for enzyme activity and Western-blot analyses were taken at the end of the experiments. Tissue biopsies were stored at $-80{ }^{\circ} \mathrm{C}$, and plasma samples at $-20{ }^{\circ} \mathrm{C}$ before later analysis.

In the second series of experiments, the groups ( $n=6$ each) and the protocols were identical with those in the first series, with the exception that the microcirculation in the affected liver lobes was investigated by means of intravital video microscopy (IVM, see later) at $t=60 \mathrm{~min}$ in the reperfusion phase.

\section{Modified lightguide spectrophotometry (O2C) device}

We used the O2C system (LEA Medizintechnik, Gießen, Germany) for noninvasive and online examination of the microcirculation, which allows the simultaneous recording of tissue oxygen saturation $\left(\mathrm{S}_{\mathrm{O}_{2}}\right.$ percentage, absolute value), tissue hemoglobin ( $\mathrm{rHb}, \mathrm{AU}$ ), capillary blood flow (AU) and capillary blood flow velocity (RBCV, AU). The O2C device combines white light spectroscopy with laser-Doppler measurement in one flat probe. To prevent the influence of regional heterogeneity and temporal blood flow variations, measurements were performed at three predetermined locations on the liver surface for 30 s each (Schreinemachers et al., 2009) with an ambient light correction before measurement.

\section{IVM}

Polymorphonuclear (PMN) leukocytes of individual vessels were examined by means of conventional fluorescence IVM (Zeiss Axiotech Vario 100HD microscope, 100 W HBO mercury lamp, Acroplan $20 \times$ water immersion objective), using in vivo fluorescence labeling. The posterior surface of the left liver lobe was exteriorized and placed on a specially designed pedestal, providing a suitable horizontal plane (Ábrahám et al., 2008). PMNs were stained in vivo by means of rhodamine-6G (Sigma, St. Louis, MO; 0.2\%, $0.1 \mathrm{ml}$, i.v.). The microscopic images were recorded with a charge-coupled device video camera (AVT HORN-BC 12) attached to a personal computer. The microcirculatory parameters were assessed off-line by frame-to-frame analysis of the recorded images, using image analysis software (IVM, Pictron Ltd., (Budapest, Hungary). The microcirculatory inflammatory reaction was assessed by calculating the number of rolling and sticking PMN leukocytes within 5 central acinar venules (diameter between 20 and $40 \mu \mathrm{m}$ ) per animal (Ábrahám et al., 2008). Rolling leukocytes were defined as cells moving at a velocity less than $40 \%$ of that of the erythrocytes in the centerline of the microvessel passing through the observed vessel segment within $30 \mathrm{~s}$, and their number was given as the number of non-adherent leukocytes per second per vessel circumference. Adherent leukocytes (stickers) were defined in each vessel segment as cells that did not move or detach from the endothelial lining within an observation period of $30 \mathrm{~s}$, and are given as the number of cells per $\mathrm{mm}^{2}$ of endothelial surface.

\section{Xanthine oxidoreductase (XOR) activity}

Tissue biopsies were homogenized in phosphate buffer ( $\mathrm{pH} 7.4$ ) containing $50 \mathrm{mM}$ Tris- $\mathrm{HCl}, 0.1 \mathrm{mM}$ EDTA, $0.5 \mathrm{mM}$ dithiothreitol, $1 \mathrm{mM}$ phenylmethylsulfonyl fluoride, $10 \mu \mathrm{g} \mathrm{ml}{ }^{-1}$ soybean trypsin inhibitor and $10 \mu \mathrm{g} \mathrm{ml}^{-1}$ leupeptin. The homogenate was centrifuged at $4{ }^{\circ} \mathrm{C}$ for $20 \mathrm{~min}$ at $24,000 \mathrm{~g}$ and the supernatant was loaded into centrifugal concentrator tubes. The activity of XOR was determined in the ultrafiltered supernatant by fluorometric kinetic assay based on the conversion of pterine to isoxanthopterine in the presence (total XOR) or absence (XO activity) of the electron acceptor methylene blue (Beckman et al., 1989). 
Myeloperoxidase (MPO) activity

Tissue MPO activity was measured in liver biopsies by the method of Kuebler et al. (1996). Briefly, the tissue was homogenized with Tris- $\mathrm{HCl}$ buffer ( $0.1 \mathrm{M}, \mathrm{pH} 7.4)$ containing $0.1 \mathrm{M}$ polymethylsulfonyl fluoride to block tissue proteases, and then centrifuged at $4{ }^{\circ} \mathrm{C}$ for $20 \mathrm{~min}$ at $24,000 \mathrm{~g}$. The MPO activities of the samples were measured at $450 \mathrm{~nm}$ (UV-1601 spectrophotometer; Shimadzu, Japan), and the data were referred to the protein content.

\section{TNF- $\alpha$ and HMGB1 levels}

Blood samples $(0.5 \mathrm{ml})$ were taken from the carotid artery into precooled DTA-containing polypropylene tubes. Samples were centrifuged at $1000 \mathrm{~g}$ for $30 \mathrm{~min}$ at $4{ }^{\circ} \mathrm{C}$, and then stored at $-70{ }^{\circ} \mathrm{C}$ until assay. Plasma TNF- $\alpha$ and HMGB1 concentrations were determined with commercially available enzyme-linked immunosorbent assays (Quantikine Ultrasensitive ELISA kit for rat TNF- $\alpha$; Biomedica Hungaria Kft, Hungary and Shino-Test Corporation ELISA kit for HMGB1; Kanagawa, Japan).

\section{Western blot analysis of NOX2 and NOX4}

Liver samples were homogenized and then lysed with RIPA buffer (Santa Cruz Biotech). Protein extracts (20 $\mu \mathrm{g}$ of total protein) were heated at $95{ }^{\circ} \mathrm{C}$ for $10 \mathrm{~min}$, then placed in ice to cool, electrophoresed in $4-15 \%$ gradient sodium dodecyl sulfate-polyacrylamide gels, and transferred onto nitrocellulose membranes (Millipore). Membranes were blocked with Tris-buffered saline (TBS) and 5\% skim milk at room temperature for $1 \mathrm{~h}$ prior to overnight incubation at $4{ }^{\circ} \mathrm{C}$ with primary antibodies against gp91phox (1:2000 dilution; Epitomics, Burlingame, CA, USA), and NOX4 (1:2000 dilution; Epitomics, Burlingame, CA, USA). After washing with TBS-T, membranes were incubated for $1 \mathrm{~h}$ at room temperature with horseradish peroxidase-conjugate-corresponding secondary antibodies (anti-rabbit, 1:2500 dilution; Promega, Madison, WI, USA). The membranes were then developed with the SuperSignal West Pico horseradish peroxidase substrate kit (Pierce, Rockford, IL, USA) and intensities of protein bands were quantitated and photographed on a Lumi-Imager ${ }^{\mathrm{TM}}$ (Roche-Diagnostics, Boehringer Mannheim, Germany) image station. For the control of sample loading and protein transfer, the membranes were stripped and reprobed with $\beta$-actin antibody (1:1000 dilution; Sigma-Aldrich, St. Louis, MO, USA).

\section{Liver transaminase (AST, ALT and $L D H$ ) release}

Blood samples withdrawn from the carotid artery were analyzed for aspartate-aminotransferase (AST), alanine-aminotransferase (ALT) and lactate-dehydrogenase ( $\mathrm{LDH})$ by standard photometric procedures (Vitros 250 analyzer, Ortho-Clinical Diagnostics, Raritan, NJ).

\section{Statistical analysis}

Data analysis was performed with the SigmaStat statistical software (Jandel Corporation, San Rafael, CA, USA). Changes in microcirculatory parameters and liver enzyme activities between groups and within groups were analyzed by two-way ANOVA, followed by the Bonferroni test. For the evaluation of biochemical assays and ELISA data, changes in variables between groups were analyzed by one-way ANOVA on ranks, followed by the Holm-Sidak test. Western blot data were analyzed with no normal distribution with the Mann-Whitney test. $P$ values $<0.05$ were regarded as significant.

\section{Results}

\section{Microcirculatory changes}

\section{Modified lightguide spectrophotometry}

The microhemodynamic parameters, capillary blood flow, capillary blood flow velocity (RBCV), tissue oxygen saturation $\left(\mathrm{S}_{\mathrm{O}_{2}}\right)$, and tissue hemoglobin content ( $\mathrm{rHb}$ ) were assessed simultaneously and on-line in the left liver lobes (Fig. 1). Reperfusion after 60-min ischemia was not associated with significant changes in intrahepatic blood flow (Fig. 1A) as compared with the Sham group. When IR was preceded by remote IPC, however, the postischemic hepatic blood flow was significantly higher than the pre-ischemic values throughout the examination period. The RBCV in the IR group was significantly lower during reperfusion in comparison with the pre-ischemic values, and no recovery was observed during the examination period (Fig. 1B). Remote IPC, however, reversed the RBCV changes to the level measured in the Sham group. Taken together, the flow and velocity changes caused by the 60-min partial ischemia were manifested in deteriorated levels of tissue $\mathrm{S}_{\mathrm{O}_{2}}$ and $\mathrm{rHb}$, which were restored by the remote IPC protocol (Fig. 1C, D).

\section{Fluorescent IVM data}

Due to the lack of selectin molecules in the post-sinusoidal endothelium, "classical rolling" cannot be observed, but the number of PMNs exhibiting the rolling phenomenon could nevertheless be determined in the central venules. Liver IR was accompanied by an approximately 4-fold increase in the number of rolling leukocytes relative to that of the sham-operated animals (Fig. 2A). In accordance with this, the number of sticking cells also displayed a significant increase in response to liver IR (Fig. 2B). Remote IPC resulted in significant improvements in both forms of cell-to-cell interactions.

\section{Inflammatory enzyme (MPO and XOR) levels}

The PMN deposition analyzed via the MPO activity was increased significantly $180 \mathrm{~min}$ after the ischemia, together with the XOR activity, which was elevated approximately 2 -fold as compared with the shamoperated group. Remote IPC applied prior to the partial liver IR insult reduced the MPO and XOR activities almost to the sham-operated levels (Fig. 3A, B).

\section{Plasma HMGB1 and TNF- $\alpha$ levels}

Following 60-min partial liver ischemia, significantly increased HMGB1 and TNF- $\alpha$ levels were observed at $180 \mathrm{~min}$ of the reperfusion period (Fig. 4A, B). The IR-induced elevations of the plasma HMGB1 and TNF- $\alpha$ were effectively attenuated by remote IPC (Fig. 4A).

\section{NOX2 and NOX4 protein expression}

Western blot analysis of the NOX2 and NOX4 proteins revealed significant increases after partial liver IR in comparison with the shamoperated animals. The application of remote IPC before IR decreased the expression of NOX2 significantly (Fig. 5A), but did not affect the level of NOX4 expression (Fig. 5B).

\section{Hepatic enzymes in the plasma}

The animals in the sham-operated group displayed minimally increased necroenzyme levels throughout the experimental protocol as compared with the baseline values. In comparison, the IR group exhibited significantly higher AST, ALP and LDH activities during the reperfusion period, indicating significant functional damage. When the remote IPC protocol preceded liver IR (remote IPC group), the plasma levels of necroenzymes were significantly reduced in comparison with the IR group (Fig. 6). 

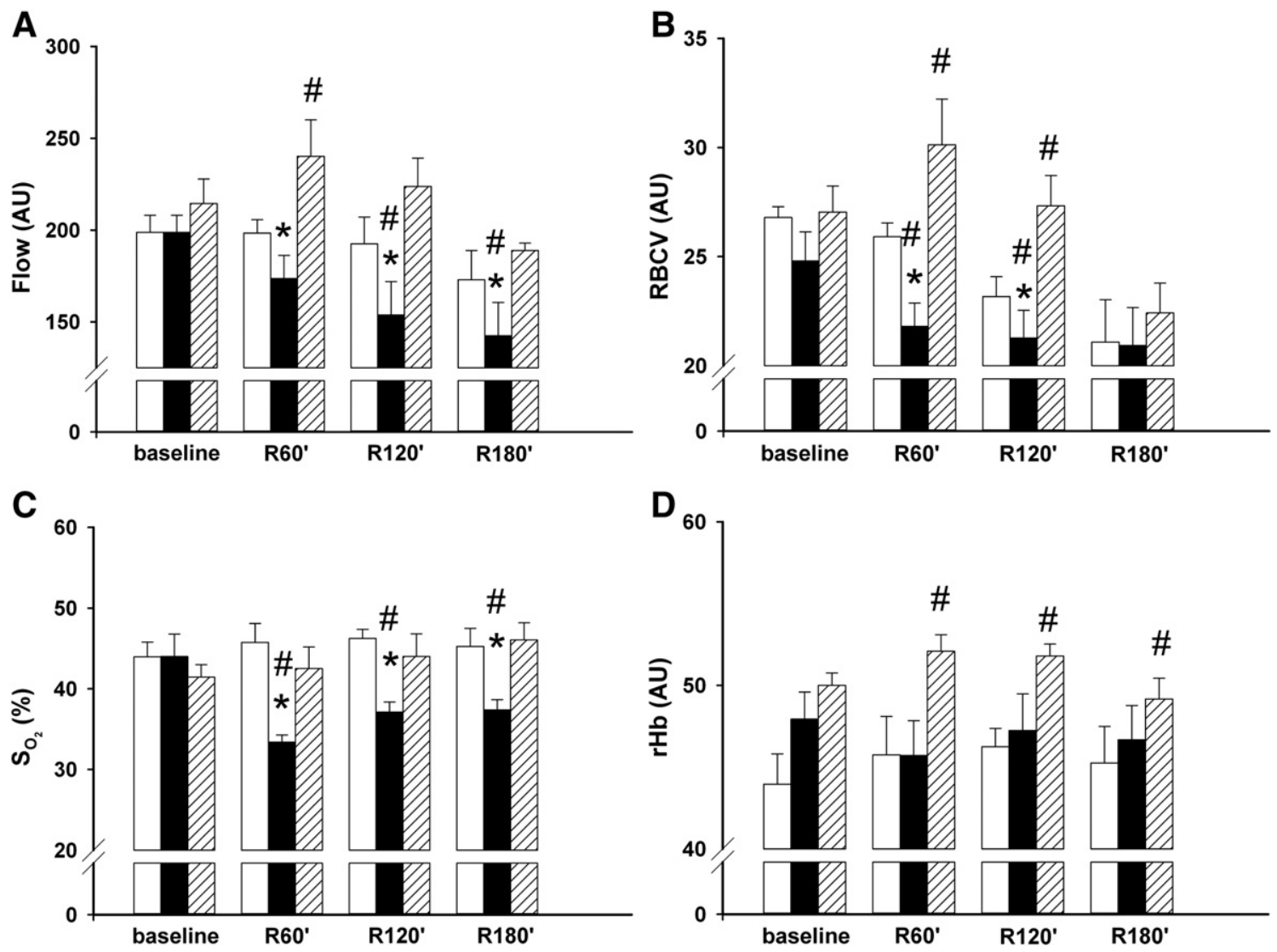

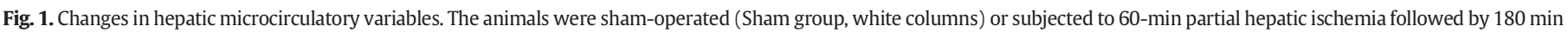

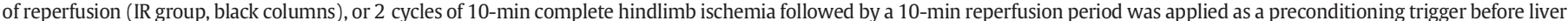

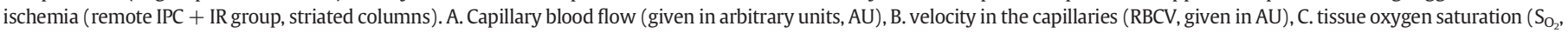
given in \%), D. tissue hemoglobin ( $\mathrm{rHb}$, given in AU). Data are presented as means \pm SEM. ${ }^{*} \mathrm{P}<0.05$ vs baseline; \#P $<0.05$ vs Sham group (two-way ANOVA, Bonferroni test).

\section{Discussion}

The major aim of this study was to investigate the effects of remote IPC after partial liver IR on enzymes that generate intracellular reactive oxygen species (ROS). The scope of this project was narrowed down to the most likely ROS-producing sources, and we focused on the most relevant isoforms, NOX2 and NOX4, whose roles in the mechanisms of IR damage or IPC have already been implicated. A partial hepatic ischemia model was used to evaluate the effects solely in response to IR, excluding poorly tolerated mesenteric congestion with the concomitant mediator release and deterioration of the systemic hemodynamics (Vollmar et al., 1994). We previously characterized the microcirculatory effects of IPC achieved by using 2 cycles of complete hindlimb ischemia on IR-induced periosteal microcirculatory derangement and systemic inflammatory responses (Szabó et al., 2009). As beneficial local effects were observed, the identical protocol was utilized to investigate the consequences of limb IPC on IR-induced inflammatory responses in a distant organ, and our study clearly demonstrated the microcirculatory benefits of remote IPC. The IR-related increases in the levels of necroenzymes and inflammatory cytokines were ameliorated and the activities of potential sources of ROS production, i.e. XOR, MPO and NOX2, were significantly reduced. The most interesting finding, however, was that the enhanced NOX4 expression was not influenced by remote IPC.

There are several possible explanations of this result. Firstly, the present findings are consistent with those of other research, which revealed that IPC inhibits the effects of mediators involved in the microcirculatory dysfunction, including ROS (Cutrn et al., 2002; Jabs et al., 2010). The main cellular sources of ROS generation in the blood vessels are the NOXs in the smooth muscle cells (Griendling et al., 2000), endothelial cells (Bayraktutan et al., 2000) and adventitial fibroblasts (Pagano et al., 1998). Among the NOX homologs, NOX4 has been reported to be the main isoform in the vascular cells (Bengtsson et al., 2003; Ellmark et al., 2005), although the expression of NOX2 or even NOX1 has also been demonstrated. Enhanced NOX4 activity has been implicated in the development of various cardiovascular pathologies, because NOX-derived superoxide rapidly reduces the bioavailability of endothelium-derived NO, thereby promoting vasoconstriction and enhancing the vascular resistance (Dusting et al., 1998; Zicha et al., 2001). Nevertheless, NOX4 within the vessel wall generates a low level of ROS continuously, even in the absence of extrinsic stimulation, and unlike phagocytic NOXs, is involved in physiological vascular processes such as maintenance of the vascular tone, regulation of the endothelium-dependent vasodilator function, oxygen sensing and modulation of the redox-sensitive signaling pathways (Dworakowski et al., 2008; Cave et al., 2006). Moreover, endothelial NOX4 acts as a constitutive endothelial generator of $\mathrm{H}_{2} \mathrm{O}_{2}$, which positively affects the vascular function, linked to signaling events that promote vasodilatation and cell protection (Dikalov et al., 2008; Takac et al., 2011). The exact factors determining the action of NOX4 in producing superoxides or $\mathrm{H}_{2} \mathrm{O}_{2}$ are unclear, but in overexpression systems NOX4 releases predominantly $\mathrm{H}_{2} \mathrm{O}_{2}$ (Ray et al., 2011). Additionally, molecular mechanisms implicated in NOX4 vasoprotection include the activation of eNOS and the increased production of NO, and the increased expression of antioxidant systems such as Nrf-2 (Schröder et al., 2012). Indeed, a significant decrease in myocardial infarct size was recently observed in NOX2- and NOX1/NOX2-, but not in NOX4-deficient mice (Braunersreuther et al., 2013). Thus, data are accumulating concerning a Janus-faced mechanism by which NOX4 can protect or cause harm to the circulatory system (Schmidt et al., 2012) and, if a defensive action of 


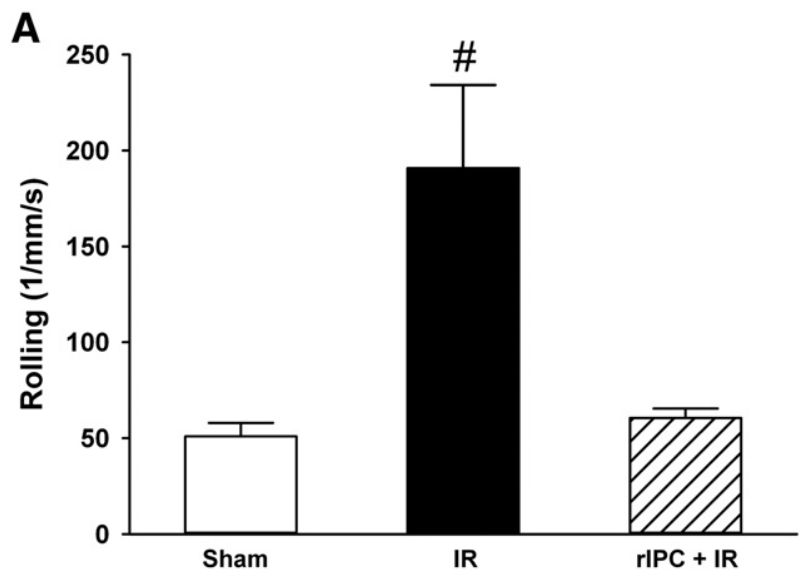

B

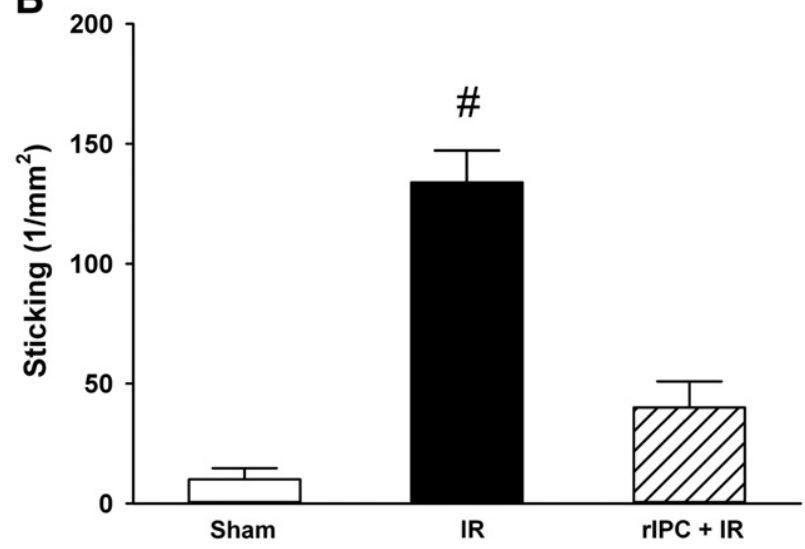

Fig. 2. Changes in PMN-endothelial interactions. A. The number of rolling PMNs in the central venules of the liver (rolling, given in $\mathrm{mm}^{-1} \mathrm{~s}^{-1}$ ), B. number of sticking PMNs (sticking, given in $\mathrm{mm}^{-2}$ ). Data are presented as means \pm SEM. $\# P<0.05$ vs Sham group (one-way ANOVA, Holm-Sidak test).

NOX4 activity is possible, it could be hypothesized that the potentially vasoprotective characteristics of NOX4 could, at least in part, explain the ineffectiveness of remote IPC in reducing the IR-related NOX4 expression.

Another possibility is that the influence of IPC is not universally effective, in consequence of the different sensitivities of the various target genes and enzymes. The remote IPC provided significant, but incomplete protection, and the residual damage and IR-induced inflammatory activation could therefore well be linked to the unchanging NOX4 activity. In this sense, the effect of IPC does not extend to all homologs (at least not to NOX4). Recent findings suggest that, unlike other ROS-generating NOXs, the tightly-assembled active conformation of NOX4 cannot be disrupted by conventional means, because the membrane-bound subunit does not require interaction with the cytosolic subunits (Csányi and Pagano, 2013).

Previous studies demonstrated that the beneficial effect of IPC extends to reducing the adherence of PMNs to the ischemic-reperfused sinusoidal endothelium, attenuating the PMN-mediated endothelial dysfunction, and limiting leukocyte accumulation in the postischemic liver tissue (Yuan et al., 2005). In accordance with these observations, the influx of activated PMNs into the postsinusoidal venules was observed in the present model, and as a result of remote IPC, the extent of rolling and sticking of the leukocytes was significantly reduced in the central venules. The mechanisms underlying PMN trafficking after IR and remote IPC can be explained in terms of several pathways leading to a modified adhesion molecule expression. The characteristic of the hepatic sinusoidal endothelium may contribute to leukocyte trapping: non-classical rolling and mainly vascular adhesion molecule-1 (VCAM1)-mediated strong adhesion occur in response to inflammation (Lee et al., 2004). NOXs have been shown to be particularly involved in regulating VCAM1 expression
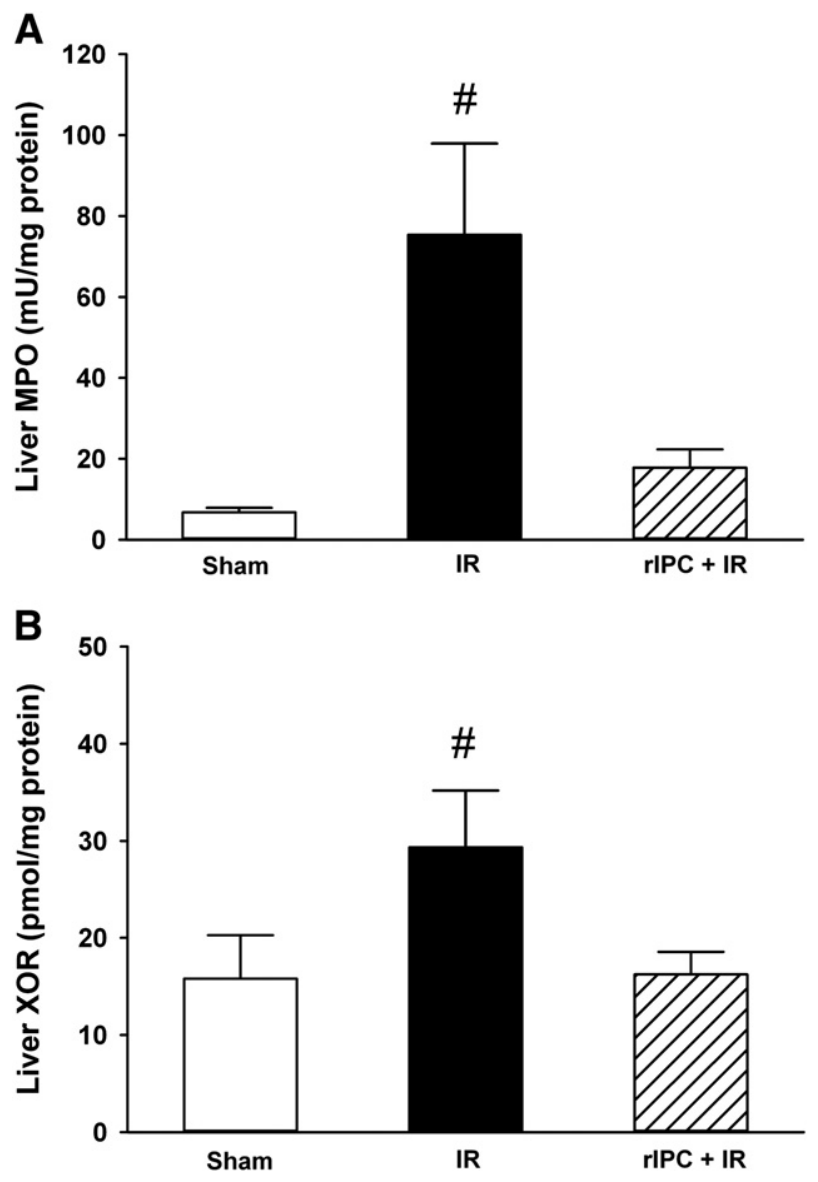

Fig. 3. Hepatic MPO and XOR activities. A. XOR activity, B. MPO activity. Data are presented as means $\pm \mathrm{SEM}$. $\# P<0.05$ vs Sham group (one-way ANOVA, Holm-Sidak test).

through TNF- $\alpha$ release (Cayatte et al., 2001). When applied in vitro, S17834, a flavonoid NOX inhibitor, directly repressed the vascular NOX activity, and it reduced TNF- $\alpha$-stimulated VCAM, ICAM- 1 and E-selectin expression in vivo (Cayatte et al., 2001). Further, the lower degree of ROS formation after remote IPC partially produced by NOXs can also be linked to reduced adhesion molecule expression. Via mineral corticoid receptor activation, aldosterone induced adhesion molecule expression also involves activation of the NOXs (Hashikabe et al., 2006). Moreover, LPS induces the expression of surface adhesion molecules through the activation of TLR4, which has been shown to be involved in the NOX-dependent activation of NF- $\kappa B$ (Park et al., 2006).

The activity of MPO, the commonly used index of PMN priming and activation (Yuan et al., 2005), further strengthened our IVM observations. As shown in the present study, the activity of MPO is significantly correlated with the number of visualized PMNs. This observation is in agreement with a previous report that accumulated PMNs were positively correlated with the development of hepatocellular damage after IR (Yuan et al., 2005). Upon activation, the prototypic isoform NOX2 has been proven to be responsible for the superoxide generation of PMNs (Babior, 1999). This isoform, also referred to as "respiratory burst oxidase", was first described in PMNs as the starting point of ROS production (Babior, 1999). The effects of NOX2-derived ROS and proteases released from activated PMNs in promoting cell death in the liver have been widely documented (Yuan et al., 2005; De Minicis et al., 2010). In the present study, remote IPC attenuated both arms of PMN-related injury: it lowered the PMN priming/MPO activity and reduced the expression of NOX2. This is in accordance with previous observations where preconditioning was induced via NOX2 in ischemic brain, myocardium and endothelial cells (Kawano et al., 2007; Milovanova et al., 2008; Thirunavukkarasu et al., 2012). 
A
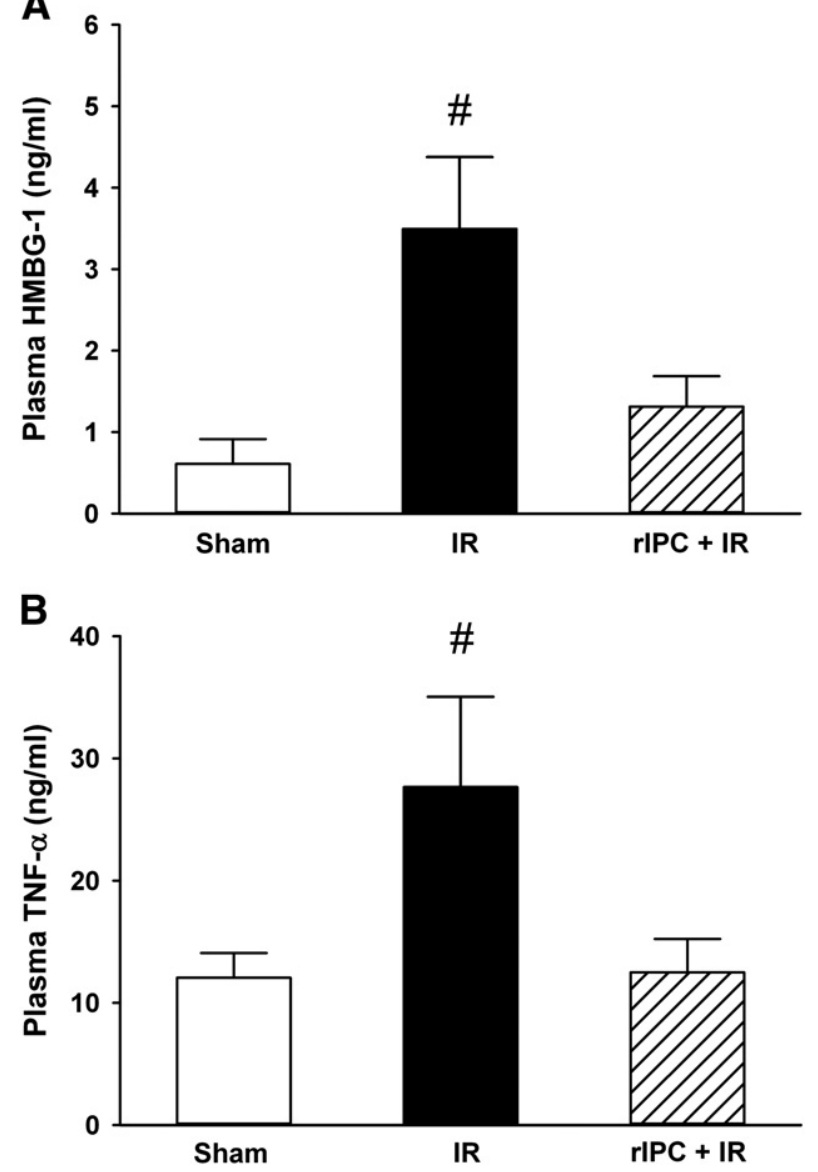

Fig. 4. Plasma cytokine levels. A. TNF- $\alpha$ level; B. HMGB1 level. Data are presented as means \pm SEM. $\# P<0.05$ vs Sham group (one-way ANOVA, Holm-Sidak test).

Cellular ROS (superoxide and $\mathrm{H}_{2} \mathrm{O}_{2}$ ) are now well recognized as playing an integral role in several growth factors and cytokine signal transduction pathways (Lander, 1997) and serve as second messengers for cellular tyrosine kinase signaling (Goldstein et al., 2005). NOXs appear to be especially involved in redox signaling because they are the only enzymes (among the many intracellular sources of superoxide formation) whose primary function is to generate ROS (Lambeth, 2004). The tissue specificity and difference in catalytic subunits offer an opportunity for the development of NOX inhibitors that do not compromise the essential physiological signaling and phagocytic functions carried out by ROS.

In this study, remote IPC significantly attenuated systemic cytokine release. It has previously been shown that NOX-mediated ROS production has a major role in the ischemia-induced inflammatory responses involving activation of the NF- $k B$ (Dworakowski et al., 2008). TNF- $\alpha$ and HMGB1 have a common NF-kB-dependent transcription; both are involved in inflammatory responses (Dworakowski et al., 2008; Kamo et al., 2013). Moreover, hepatocytes have been demonstrated to produce TNF- $\alpha$ in a NOX-dependent manner following hypoxia-reoxygenation and liver IR (Spencer et al., 2013). The relationship between TNF- $\alpha$ and HMGB1 expression and ROS production is bidirectional: TNF- $\alpha$ and HMGB1 are involved in regulating the expression of cytokines and other mediators that participate in acute inflammatory responses, many of which are associated with the increased generation of ROS (Kamo et al., 2013). On the other hand, oxidative stress has been reported to up-regulate the expression of cytokines that promote inflammatory responses during reperfusion. These antigen-independent responses interact and amplify each other, finally leading to impaired microhemodynamics, functional and structural cell damage, and remote or systemic inflammatory complications.
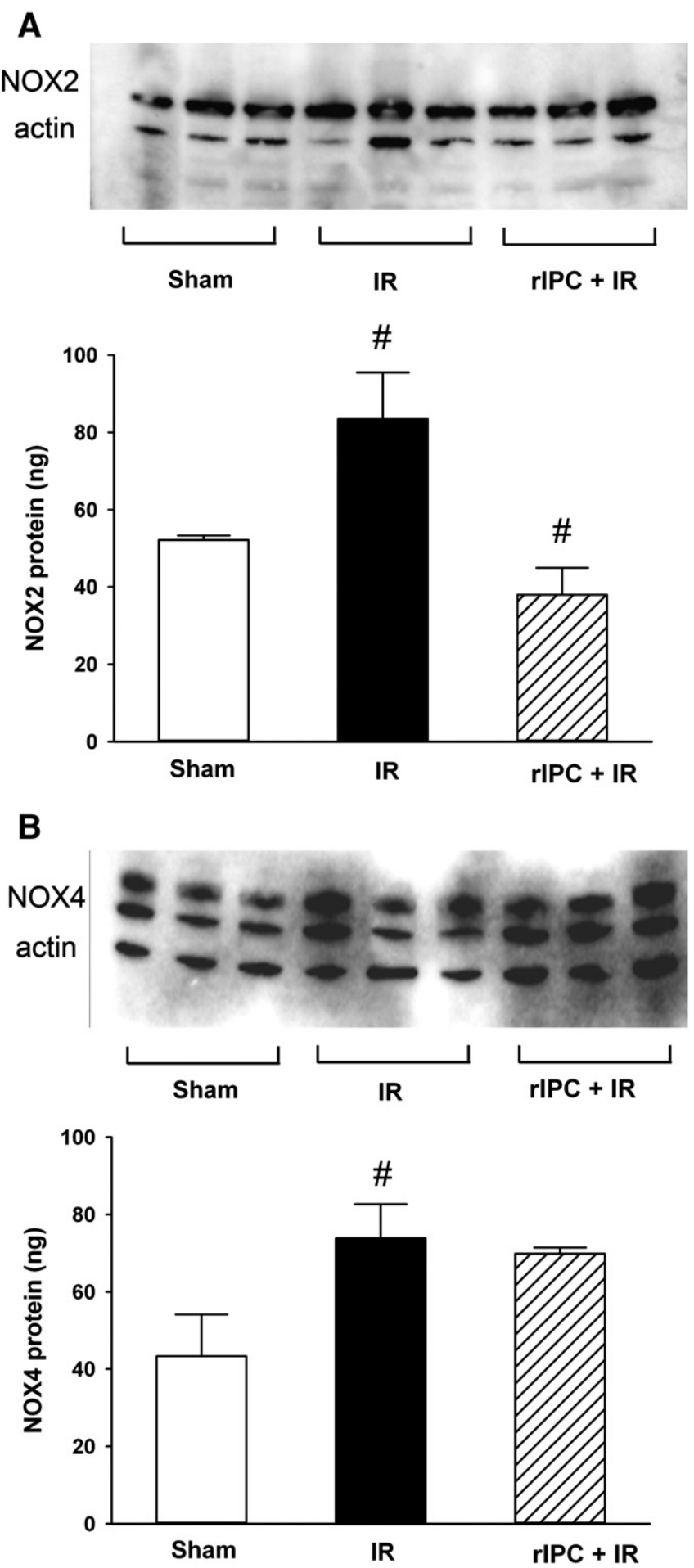

Fig. 5. Hepatic expressions of NOX2 and NOX4 proteins. A. NOX2 expression; B. NOX4 expression. Data are presented as medians \pm SD. $\# P<0.05$ vs Sham group (Mann-Whitney test)

\section{Conclusions}

Remote IPC exerted marked protection against the potentially detrimental microcirculatory consequences of hepatic IR. This accords with the lower levels of generation of inflammatory mediators, preserved liver blood flow and oxygenation. The signs of PMN activation and the induction of NOX2 were likewise weaker, but in contrast with expectations, the expression of NOX4, the main vascular NOX isoform, was not 

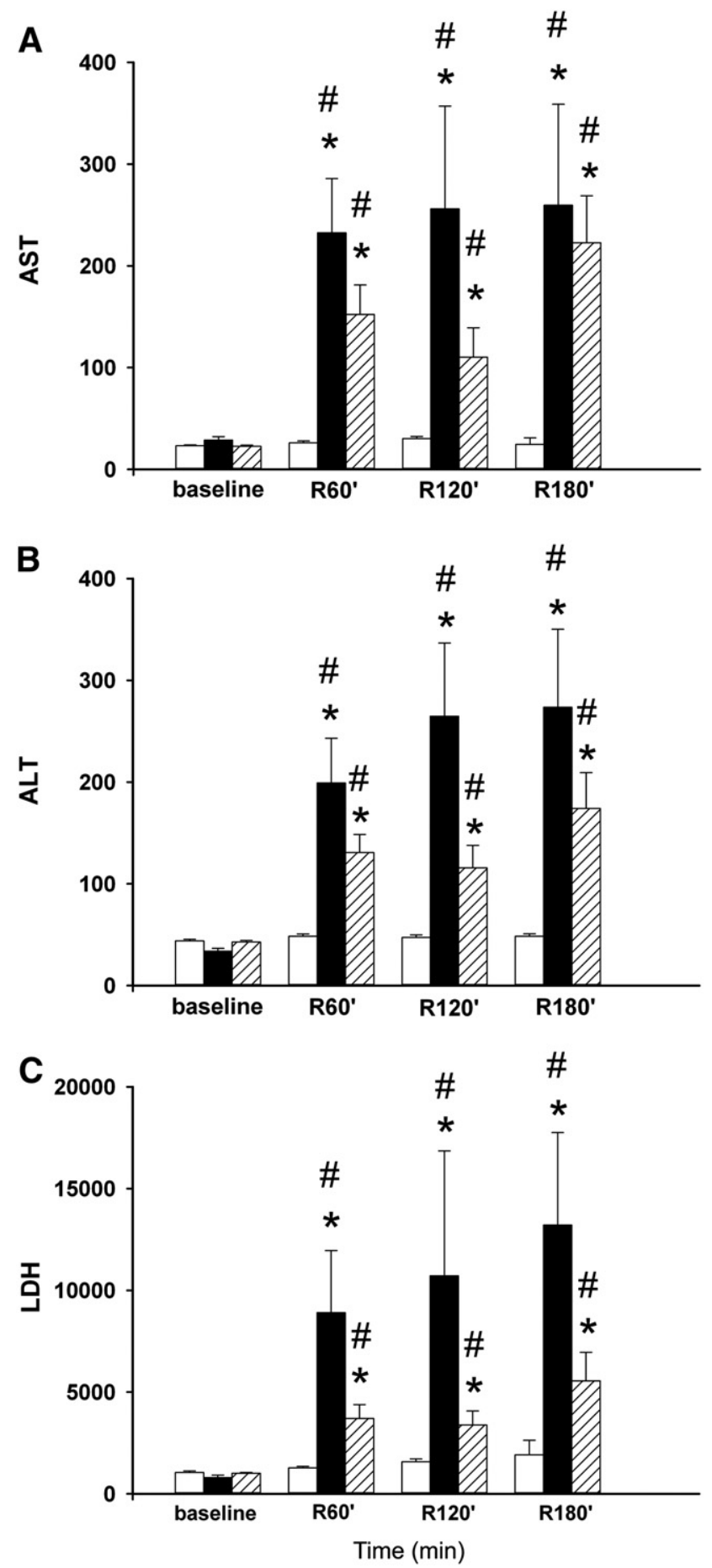

Fig. 6. Time courses of plasma AST, ALT and LDH changes. The animals were shamoperated (Sham group, white columns) or subjected to 60-min partial hepatic ischemia followed by 180 min of reperfusion (IR group, black columns) or 2 cycles of 10-min complete hindlimb ischemia followed by a 10 -min reperfusion period was applied as a preconditioning trigger before liver ischemia (remote IPC + IR group, striated columns). A. AST levels (AST, given in U/L), B. ALT levels (ALT, given in U/L), C. LDH levels (LDH given in $\mathrm{U} / \mathrm{L}$ ). Data are presented as means \pm SEM. ${ }^{*} P<0.05$ vs baseline; $\# P<0.05$ vs Sham group (two-way ANOVA, Bonferroni test).

attenuated. Several questions remain unanswered, but further characterization of "ischemia-specific" enzymatic sources may lead to the preventive targeting of oxido-reductive stress, rather than the scavenging of ROS after they have been formed.
Conflict of interest statement

The authors declare that there are no conflicts of interest.

\section{Acknowledgments}

PH was supported by a European Society for Surgical Research (ESSR) Fellowship Award. The study was supported by Hungarian Science Research Fund (OTKA) grant K104656 and Social Renewal Operational Programs (TÁMOP)-4.2.2/A-11/1/KONV-2012-0035 and (TÁMOP)-4.2.2/ A-11/1/KONV-2012-0073.

\section{References}

Ábrahám S, Szabó A, Kaszaki J, Varga R, Eder K, Duda E, et al. Kupffer cell blockade improves the endotoxin-induced microcirculatory inflammatory response in obstructive jaundice. Shock 2008;30:69-74. http://dx.doi.org/10.1097/SHK.0b013e31815dceea. [PMID: 18562926].

Abu-Amara M, Yang SY, Quaglia A, Rowley P, Fuller B, Seifalian A, et al. Role of endothelial nitric oxide synthase in remote ischemic preconditioning of the mouse liver. Liver Transpl 2011;17:610-9. http://dx.doi.org/10.1002/lt.22272. [PMID: 21506249].

Anilkumar N, Sirker A, Shah AM. Redox sensitive signaling pathways in cardiac remodeling, hypertrophy and failure. Front Biosci (Landmark Ed) 2009;14:3168-87. [PMID: 19273265].

Babior BM. NADPH oxidase: an update. Blood 1999;93:1464-76. [PMID: 10029572]

Bayraktutan U, Blayney L, Shah AM. Molecular characterization and localization of the $\mathrm{NAD}(\mathrm{P}) \mathrm{H}$ oxidase components gp91-phox and p22-phox in endothelial cells. Arterioscler Thromb Vasc Biol 2000;20:1903-11. http://dx.doi.org/10.1161/01.ATV.20. 8.1903. [PMID: 10938010].

Beckman JS, Parks DA, Pearson JD, Marshall PA, Freeman BA. A sensitive fluorometric assay for measuring xanthine dehydrogenase and oxidase in tissues. Free Radic Biol Med 1989;6:607. [PMID: 2753392].

Bedard K, Krause KH. The NOX family of ROS-generating NADPH oxidases: physiology and pathophysiology. Physiol Rev 2007;87:245-313. http://dx.doi.org/10.1152/ physrev.00044.2005. [PMID: 17237347\}.

Bengtsson SH, Gulluyan LM, Dusting GJ, Drummond GR. Novel isoforms of NADPH oxidase in vascular physiology and pathophysiology. Clin Exp Pharmacol Physiol 2003; 30:849-54. http://dx.doi.org/10.1046/j.1440-1681.2003.03929.x. [PMID: 14678249].

Braunersreuther V, Montecucco F, Ashri M, Pelli G, Galan K, Frias M, et al. Role of NADPH oxidase isoforms NOX1, NOX2 and NOX4 in myocardial ischemia/reperfusion injury. Mol Cell Cardiol 2013;64:99-107. http://dx.doi.org/10.1016/j.yjmcc.2013.09.007. [PMID: 24051369].

Cave AC, Brewer AC, Narayanapanicker A, Ray R, Grieve DJ, Walker S, et al. NADPH oxidases in cardiovascular health and disease. Antioxid Redox Signal 2006;8:691-728. http://dx.doi. org/10.1089/ars.2006.8.691. [PMID: 16771662].

Cayatte AJ, Rupin A, Oliver-Krasinski J, Maitland K, Sansilvestri-Morel P, Boussard MF, et al. S17834, a new inhibitor of cell adhesion and atherosclerosis that targets NADPH oxidase. Arterioscler Thromb Vasc Biol 2001;21:1577-84. http://dx.doi.org 10.1161/hq1001.096723. [PMID: 11597929].

Csányi G, Pagano PJ. Strategies aimed at Nox4 oxidase inhibition employing peptides from Nox4 B-loop and C-terminus and p22 (phox) N-terminus: an elusive target. Int J Hypertens 2013:842827. http://dx.doi.org/10.1155/2013/842827. [PMID: 23606947].

Cutrn JC, Perrelli MG, Cavalieri B, Peralta C, Rosell Catafau J, Poli G. Microvascular dysfunction induced by reperfusion injury and protective effect of ischemic preconditioning Free Radic Biol Med 2002;33:1200-8. http://dx.doi.org/10.1016/S0891-5849(02) 01017-1. [PMID: 12398928].

De Minicis S, Seki E, Paik YH, Osterreicher CH, Kodama Y, Kluwe J, et al. Role and cellular source of nicotinamide adenine dinucleotide phosphate oxidase in hepatic fibrosis Hepatology 2010;52:1420-30. http://dx.doi.org/10.1002/hep.23804. [PMID: 20690191].

Dikalov SI, Dikalova AE, Bikineyeva AT, Schmidt HH, Harrison DG, Griendling KK. Distinct roles of Nox1 and Nox4 in basal and angiotensin II-stimulated superoxide and hydrogen peroxide production. Free Radic Biol Med 2008;45:1340-51. http://dx.doi.org/10 1016/j.freeradbiomed.2008.08.013. [PMID: 18760347].

Dusting GJ, Fennessy P, Yin ZL, Gurevich V. Nitric oxide in atherosclerosis: vascular protector or villain? Clin Exp Pharmacol Physiol Suppl 1998;25:S34-41. [PMID: 9809190]

Dworakowski R, Alom-Ruiz SP, Shah AM. NADPH oxidase-derived reactive oxygen species in the regulation of endothelial phenotype. Pharmacol Rep 2008;60:21-8. [PMID: 18276982].

Ellmark SHM, Dusting GJ, Ng TangFui M, Guzzo-Pernell N, Drummond GR. The contribution of Nox4 to NADPH oxidase activity in mouse vascular smooth muscle. Cardiovasc Res 2005;65:495-504. http://dx.doi.org/10.1016/j.cardiores.2004.10.026. [PMID: 15639489].

Goldstein BJ, Mahadev K, Wu X. Redox paradox: insulin action is facilitated by insulinstimulated reactive oxygen species with multiple potential signaling targets. Diabetes 2005;54:311-21. http://dx.doi.org/10.2337/diabetes.54.2.311. [PMID: 15677487].

Görlach A, Brandes RP, Nguyen K, Amidi M, Dehghani F, Busse R. A gp91phox containing NADPH oxidase selectively expressed in endothelial cells is a major source of oxygen radical generation in the arterial wall. Circ Res 2000;87:26-32. http://dx.doi.org/10. 1161/01.RES.87.1.26. [PMID: 10884368].

Griendling KK, Sorescu D, Lassègue B, Ushio-Fukai M. Modulation of protein kinase activity and gene expression by reactive oxygen species and their role in vascular physiology and pathophysiology. Arterioscler Thromb Vasc Biol 2000;20:2175-83. http://dx.doi.org/10.1161/01.ATV.20.10.2175. [PMID: 11031201]. 
Harada H, Hines IN, Flores S, Gao B, McCord J, Scheerens H, et al. Role of NADPH oxidasederived superoxide in reduced size liver ischemia and reperfusion injury. Arch Biochem Biophys 2004;423:103-8. http://dx.doi.org/10.1016/j.abb.2003.08.035. [PMID: 14871473].

Hashikabe Y, Suzuki K, Jojima T, Uchida K, Hattori Y. Aldosterone impairs vascular endothelia cell function. J Cardiovasc Pharmacol 2006;47:609-13. http://dx.doi.org/10.1097/01.fjc. 0000211738.63207.c3. [PMID: 16680076].

Jabs A, Fasola F, Muxel S, Münzel T, Gori T. Ischemic and non-ischemic preconditioning: endothelium-focused translation into clinical practice. Clin Hemorheol Microcirc 2010;45:185-91. http://dx.doi.org/10.3233/CH-2010-1297. [PMID: 20675899].

Kamo N, Ke B, Ghaffari AA, Shen XD, Busuttil RW, Cheng G, et al. ASC/caspase-1/IL-1ß signaling triggers inflammatory responses by promoting HMGB1 induction in liver ischemia/ reperfusion injury. Hepatology 2013;58:351-62. http://dx.doi.org/10.1002/hep.26320. [PMID: 23408710].

Kawano T, Kunz A, Abe T, Girouard H, Anrather J, Zhou P, et al. NOS-derived NO and Nox2 derived superoxide confer tolerance to excitotoxic brain injury through peroxynitrite. J Cereb Blood Flow Metab 2007;27:1453-62. http://dx.doi.org/10.1038/sj.jcbfm. 9600449. [PMID: 17293848].

Koti RS, Yang W, Dashwood MR, Davidson BR, Seifalian AM. Effect of ischemic preconditioning on hepatic microcirculation and function in a rat model of ischemia reperfusion injury. Liver Transpl 2002;8:1182-91. http://dx.doi.org/10.1053/jlts.2002.36846. [PMID: 12474159].

Kuebler WM, Abels C, Schuerer L, Goetz AE. Measurement of neutrophil content in brain and lung tissue by a modified myeloperoxidase assay. Int J Microcirc Clin Exp 1996;16:89. [PMID: 8737712].

Lambeth JD. NOX enzymes and the biology of reactive oxygen. Nat Rev Immunol 2004;4: 181-9. http://dx.doi.org/10.1038/nri1312. [PMID: 15039755].

Lander HM. An essential role for free radicals and derived species in signal transduction. FASEB J 1997;11:118-24. [PMID: 9039953].

Lassègue B, Sorescu D, Szöcs K, Yin Q Akers M, Zhang Y, et al. Novel gp91(phox) homologues in vascular smooth muscle cells: Nox1 mediates angiotensin II-induced superoxide formation and redox-sensitive signaling pathways. Circ Res 2001;88:888-94. http://dx. doi.org/10.1161/hh0901.090299. [PMID:11348997].

Lee YS, Kang YS, Lee JS, Nicolova S, Kim JA. Involvement of NADPH oxidase-mediated generation of reactive oxygen species in the apototic cell death by capsaicin in HepG2 human hepatoma cells. Free Radic Res 2004;38:405-12. [PMID: 15190937].

Mallick IH, Yang W, Winslet MC, Seifalian AM. Ischaemic preconditioning improves microvascular perfusion and oxygenation following reperfusion injury of the intestine. $\mathrm{Br} \mathrm{J}$ Surg 2005;92:1169-76. http://dx.doi.org/10.1002/bjs.4988. [PMID: 16044427].

Marden JJ, Zhang Y, Oakley FD, Zhou W, Luo M, Jia HP, et al. JunD protects the liver from ischemia/reperfusion injury by dampening AP-1 transcriptional activation. J Biol Chem 2008;283:6687-95. http://dx.doi.org/10.1074/jbc.M705606200. [PMID: 18182393].

Milovanova T, Chatterjee S, Hawkins BJ, Hong N, Sorokina EM, Debolt K, et al. Caveolae are an essential component of the pathway for endothelial cell signaling associated with abrupt reduction of shear stress. Biochim Biophys Acta 2008;1783:1866-75. http:// dx.doi.org/10.1016/j.bbamcr.2008.05.010. [PMID: 18573285].

Pagano PJ, Chanock SJ, Siwik DA, Colucci WS, Clark JK. Angiotensin II induces p67phox mRNA expression and NADPH oxidase superoxide generation in rabbit aortic adventitial fibroblasts. Hypertension 1998;32:331-7. http://dx.doi.org/10.1161/01.HYP.32. 2.331. [PMID: 9719063].

Park HS, Chun JN, Jung HY, Choi C, Bae YS. Role of NADPH oxidase 4 in lipopolysaccharideinduced proinflammatory responses by human aortic endothelial cells. Cardiovasc Res 2006;72:447-55. http://dx.doi.org/10.1016/j.cardiores.2006.09.012. [PMID: 17064675]
Ray R, Murdoch CE, Wang M, Santos CX, Zhang M, Alom-Ruiz S, et al. Endothelial Nox4 NADPH oxidase enhances vasodilatation and reduces blood pressure in vivo. Arterioscler Thromb Vasc Biol 2011;31:1368-76. http://dx.doi.org/10.1161/ATVBAHA.110.219238. [PMID: 21415386]

Schmidt HH, Wingler K, Kleinschnitz C, Dusting G. NOX4 is a Janus-faced reactive oxygen species generating NADPH oxidase. Circ Res 2012;111:e15-6. http://dx.doi.org/10. 1161/CIRCRESAHA.112.271957. [PMID: 22723224].

Schreinemachers MC, Doorschodt BM, Florquin S, van den Bergh Weerman MA, Reitsma JB, Lai W, et al. Improved preservation and microcirculation with polysol after transplantation in a porcine kidney autotransplantation model. Nephrol Dial Transplant 2009;24:816. http://dx.doi.org/10.1093/ndt/gfn559. [PMID: 18849394].

Schröder K, Zhang M, Benkhoff S, Mieth A, Pliquett R, Kosowski J, et al. Nox4 is a protective reactive oxygen species generating vascular NADPH oxidase. Circ Res 2012;110: 1217-25. http://dx.doi.org/10.1161/CIRCRESAHA.112.267054. [PMID: 22456182].

Sorescu D, Griendling KK. Reactive oxygen species, mitochondria, and NAD(P)H oxidases in the development and progression of heart failure. Congest Heart Fail 2002;8: 132-40. http://dx.doi.org/10.1111/j.1527-5299.2002.00717.x. [PMID: 12045381].

Spencer NY, Zhou W, Li Q, Zhang Y, Luo M, Yan Z, et al. Hepatocytes produce TNF- $\alpha$ following hypoxia-reoxygenation and liver ischemia-reperfusion in a NADPH oxidase- and c-Src-dependent manner. Am J Physiol Gastrointest Liver Physiol 2013;305:G84-94. http://dx.doi.org/10.1152/ajpgi.00430.2012. [PMID: 23639811].

Szabó A Varga R, Keresztes M, Vízler C, Németh I Rázga Z et al. Ischemic limb preconditioning downregulates systemic inflammatory activation. J Orthop Res 2009;27: 897-902. http://dx.doi.org/10.1002/jor.20829. [PMID: 19105227].

Takac I, Schröder K, Zhang L, Lardy B, Anilkumar N, Lambeth JD, et al. The E-loop is involved in hydrogen peroxide formation by the NADPH oxidase Nox4. J Biol Chem 2011;286:13304-13. http://dx.doi.org/10.1074/jbc.M110.192138. [PMID: 21343298].

Taniguchi M, Uchinami M, Doi K, Yoshida M, Sasaki H, Tamagawa K, et al. Edaravone reduces ischemia-reperfusion injury mediators in rat liver. J Surg Res 2007;137:69. http://dx.doi.org/10.1016/j.jss.2006.06.033. [PMID: 17064733].

Tejima K, Arai M, Ikeda H, Tomiya T, Yanase M, Inoue Y, et al. Induction of ischemic tolerance in rat liver via reduced nicotinamide adenine dinucleotide phosphate oxidase in Kupffer cells. World J Gastroenterol 2007;13:5071-8. [PMID: 17876872].

Thirunavukkarasu M, Adluri RS, Juhasz B, Samuel SM, Zhan L, Kaur A, et al. Novel role of NADPH oxidase in ischemic myocardium: a study with Nox2 knockout mice. Funct Integr Genomics 2012;12:501-14. http://dx.doi.org/10.1007/s10142-011-0256-x. [PMID: 22038056].

Vollmar B, Glasz J, Leiderer R, Post S, Menger MD. Hepatic microcirculatory perfusion failure is a determinant of liver dysfunction in warm ischemia-reperfusion. Am J Pathol 1994;145:1421-31. [PMID: 7992845].

Wang Q, Sun AY, Simonyi A, Kalogeris TJ, Miller DK, Sun GY, et al. Ethanol preconditioning protects against ischemia/reperfusion-induced brain damage: role of NADPH oxidase-derived ROS. Free Radic Biol Med 2007;43:1048-60. http://dx.doi.org/10. 1016/j.freeradbiomed.2007.06.018. [PMID: 17761301].

Yuan GJ, Ma JC, Gong ZJ, Sun XM, Zheng SH, Li X. Modulation of liver oxidant-antioxidant system by ischemic preconditioning during ischemia/reperfusion injury in rats. World J Gastroenterol 2005;11:1825-8. [PMID: 15793874]

Yuan HJ, Zhu XH, Luo Q Wu YN, Kang Y, Jiao JJ, et al. Noninvasive delayed limb ischemic preconditioning in rats increases antioxidant activities in cerebral tissue during severe ischemia-reperfusion injury. J Surg Res 2012;174:176-83. http://dx.doi.org/ 10.1016/j.jss.2010.11.001. [PMID: 21195427].

Zicha J, Dobesová Z, Kunes J. Relative deficiency of nitric oxide-dependent vasodilation in salt-hypertensive Dahl rats: the possible role of superoxide anions. J Hypertens 2001; 19:247-54. [PMID: 11212967]. 